University of Nebraska - Lincoln

DigitalCommons@University of Nebraska - Lincoln

April 1997

\title{
Enhanced temperature effect on magnetoresistance in Fe/Mo multilayers
}

M.L. Yan

State Key Laboratory for Magnetism, Institute of Physics, Chinese Academy of Sciences, Beijing, China

Y.W. Lai

State Key Laboratory for Magnetism, Institute of Physics, Chinese Academy of Sciences, Beijing, China

L. Yin

State Key Laboratory for Magnetism, Institute of Physics, Chinese Academy of Sciences, Beijing, China

Sy_Hwang Liou

University of Nebraska-Lincoln, sliou@unl.edu

Follow this and additional works at: https://digitalcommons.unl.edu/physicsliou

Part of the Physics Commons

Yan, M.L.; Lai, Y.W.; Yin, L. ; and Liou, Sy_Hwang, "Enhanced temperature effect on magnetoresistance in Fe/Mo multilayers" (1997). Si-Hwang Liou Publications. 68.

https://digitalcommons.unl.edu/physicsliou/68

This Article is brought to you for free and open access by the Research Papers in Physics and Astronomy at DigitalCommons@University of Nebraska - Lincoln. It has been accepted for inclusion in Si-Hwang Liou Publications by an authorized administrator of DigitalCommons@University of Nebraska - Lincoln. 


\title{
High coercivity rare earth-cobalt films
}

\author{
S. S. Malhotra \\ Behlen Laboratory of Physics and Center for Materials Research and Analysis, University of Nebraska, \\ Lincoln, Nebraska 68588-0111 \\ Y. Liu \\ Center for Materials Research and Analysis, University of Nebraska, Lincoln, Nebraska 68588-0111 and \\ Department of Mechanical Engineering, University of Nebraska, Lincoln, Nebraska 68588-0656
}

\section{Z. S. Shan, S. H. Liou, D. C. Stafford, and D. J. Sellmyer \\ Behlen Laboratory of Physics and Center for Materials Research and Analysis, University of Nebraska, Lincoln, Nebraska 68588-0111}

\begin{abstract}
Rare earth-cobalt ( $\mathrm{RCo}, \mathrm{R}=\mathrm{Sm}, \mathrm{Pr}$ ) films with thicknesses from 30 to $700 \mathrm{~nm}$ have been prepared with and without a $\mathrm{Cr}$ underlayer by dc magnetron sputtering from a $\mathrm{R}_{2} \mathrm{Co}_{7}$ composite target. The as-deposited SmCo films with a $\mathrm{Cr}$ underlayer $(\mathrm{SmCo} \| \mathrm{Cr})$ have magnetic coercivities of about 500-2800 Oe and the PrCo $\| \mathrm{Cr}$ films have coercivities of about 100-300 Oe, but after annealing at $500{ }^{\circ} \mathrm{C}$ coercivities as high as $31 \mathrm{kOe}$ for $\mathrm{SmCo} \| \mathrm{Cr}$ films and $10 \mathrm{kOe}$ for PrCo $\| \mathrm{Cr}$ films were observed. The as-deposited PrCo films are composed mostly of an amorphous phase with about 30 vol \% of crystallites but after annealing at $500{ }^{\circ} \mathrm{C}$ the film is transformed completely to crystallites of about $10 \mathrm{~nm}$ diameter as revealed by high-resolution transmission electron microscopy (HRTEM). Nanodiffraction and HRTEM studies show that the crystallites have a closed-packed hexagonal structure. HRTEM study also shows that the annealed SmCo films with a Cr underlayer have grain sizes of about $20 \mathrm{~nm}$ and the SmCo films without the $\mathrm{Cr}$ underlayer have grain sizes of about $10 \mathrm{~nm}$. The large increase in coercivity for the annealed films is due to the growth of the crystallites. (C) 1996 American Institute of Physics. [S0021-8979(96)33808-1]
\end{abstract}

\section{INTRODUCTION}

Thin films of hard magnetic materials such as rare earth-transition metal alloys are of interest for device applications and magnetic recording media. Among rare earth semi-hard magnetic films, SmCo films with a $\mathrm{Cr}$ underlayer prepared at room temperature with high magnetic coercivity $\left(H_{c}\right)$ of 3-4 kOe, small grain size and high uniaxial anisotropy have shown good potential for high density recording media. ${ }^{1-3}$ Velu et al. ${ }^{4}$ have shown that $\mathrm{SmCo}_{4}$ films on a $\mathrm{Cr}$ underlayer have a coercivity value of $3 \mathrm{kOe}$ at room temperature. Recently, Okumura et al. ${ }^{5}$ reported $H_{c}$ of about 3.5 $\mathrm{kOe}$ for $\mathrm{Sm}_{15} \mathrm{Co}_{85} \| \mathrm{Cr}$ films. Liu et al. ${ }^{6-8}$ reported systematic studies of the microstructure of SmCo $\| \mathrm{Cr}$ films including the $\mathrm{Cr}$ underlayer, SmCo layer, and the nanocrystallites in the SmCo layer. The dependence of $H_{c}$ on the SmCo composition $^{1-3}$ is unclear but it has been shown that the $H_{c}$ strongly depends on the sputtering condition such as substrate temperature and Ar pressure during deposition of $\mathrm{Cr}$ and SmCo. This dependence may be related to the microstructure of the films. The $\mathrm{Cr}$ underlayer helps to increase the coercivity by controlling the grain size and morphology of the SmCo layer and also improves the in-plane magnetization. Hence if crystallinity and grain growth is promoted in the SmCo layer a much higher value of coercivity can be obtained. This can be achieved by either depositing the film at high substrate temperature or by post-annealing the asdeposited films. A coercivity of $30 \mathrm{kOe}$ was obtained for 4000- $\AA$-thick $\mathrm{Co}_{3.65} \mathrm{Cu}_{1.35} \mathrm{Sm}$ films prepared at substrate temperature of $600{ }^{\circ} \mathrm{C}$ by Theurer et al. ${ }^{9}$ Cadieu et al. ${ }^{10}$ have shown that $\mathrm{SmCo}_{5}$ films directly crystallized on to a heated substrate have $H_{c}$ of about $23 \mathrm{kOe}$. The reason for this high coercivity was associated with the high magnetic anisotropy and the fine grain structure.
In the rare earth-cobalt system the low Co phase adjacent to $\mathrm{SmCo}_{5}$ is in general of the $\mathrm{Sm}_{2} \mathrm{Co}_{7}$ type which has reasonably high anisotropy field $H_{A}>200 \mathrm{kOe} .{ }^{11}$ The PrCo compounds also feature excellent intrinsic magnetic properties comparable to the SmCo compounds. The $\mathrm{Pr}_{2} \mathrm{Co}_{7}$ phase has $H_{A}>100 \mathrm{kOe}{ }^{11}$ and the $\operatorname{Pr}_{5} \mathrm{Co}_{19}$ phase has $H_{A}>38$ kOe. ${ }^{12}$ In this work we report the effect of post-annealing for $\mathrm{Pr}_{2} \mathrm{Co}_{7}$ and $\mathrm{Sm}_{2} \mathrm{Co}_{7}$ films with and without the $\mathrm{Cr}$ underlayer.

\section{EXPERIMENTAL PROCEDURE}

$\mathrm{R}_{2} \mathrm{Co}_{7}(\mathrm{R}=\mathrm{Sm}, \mathrm{Pr})$ films with thickness from 30 to 700 $\mathrm{nm}$ were prepared with and without a $\mathrm{Cr}$ underlayer by $\mathrm{dc}$ magnetron sputtering from a composite target. All the films have a $\mathrm{Cr}$ overlayer of $10 \mathrm{~nm}$ to protect the RCo layer. The $\mathrm{Sm}_{2} \mathrm{Co}_{7}$ target was made by pressing the $\mathrm{Sm}_{2} \mathrm{Co}_{7}$ powder and then sintering in vacuum at $1100{ }^{\circ} \mathrm{C}$ for $30 \mathrm{~min}$ and the $\mathrm{Pr}_{2} \mathrm{Co}_{7}$ target was made by pressing the $\mathrm{Pr}_{2} \mathrm{Co}_{7}$ powder and then sintering in vacuum for $30 \mathrm{~min}$ at $1050{ }^{\circ} \mathrm{C}$. The $\mathrm{Cr}$ target was obtained commercially and had a $99.9 \%$ purity. The base pressure of the sputtering system was $5 \times 10^{-8}$ Torr and the Ar pressure during sputtering was 20 mTorr. The sputtering rate for $\mathrm{Pr}_{2} \mathrm{Co}_{7}$ and $\mathrm{Sm}_{2} \mathrm{Co}_{7}$ was $1.1 \AA$ A/s and for Cr was $5 \AA / s$.

The magnetic properties of the films were measured with an alternating gradient force magnetometer (AGFM) and SQUID magnetometer. The composition of the films was analyzed by energy dispersive $\mathrm{X}$-ray analysis (EDAX) and was found to be close to the target composition. The structure was studied by $\mathrm{x}$-ray diffraction and high resolution electron microscopy (HRTEM). 


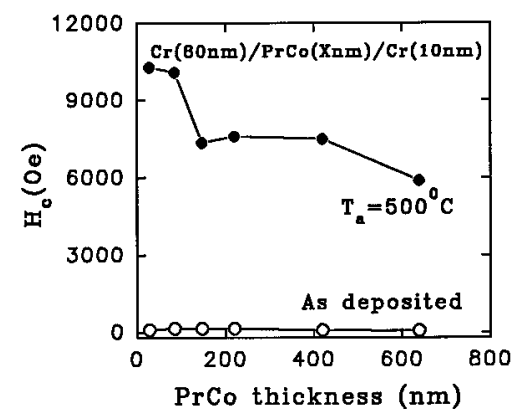

FIG. 1. Coercivity vs PrCo layer thickness for the as-deposited and annealed at $500{ }^{\circ} \mathrm{C} \mathrm{PrCo} \| \mathrm{Cr}$ films with a $\mathrm{Cr}$ underlayer of $80 \mathrm{~nm}$.

\section{RESULTS AND DISCUSSION}

We first discuss the magnetic and structural properties for the as-deposited and annealed PrCo films. Figure 1 shows the dependence of the coercivity on the PrCo layer thickness for the $\mathrm{PrCo} \| \mathrm{Cr}$ films with a $\mathrm{Cr}$ underlayer of $80 \mathrm{~nm}$. The as-deposited films show a coercivity of only about 100-300 Oe but after annealing at $500{ }^{\circ} \mathrm{C}$ in vacuum for $20 \mathrm{~min}$ there is a large enhancement of coercivity. The $H_{c}$ of the films annealed at $500{ }^{\circ} \mathrm{C}$ decreases from about 10 to $5.9 \mathrm{kOe}$ as the film thickness increases from 28 to $640 \mathrm{~nm}$. It was also observed for the 28-nm-thick $\mathrm{PrCo} \| \mathrm{Cr}$ film that upon annealing up to $350{ }^{\circ} \mathrm{C}, H_{c}$ was nearly unchanged but at $400{ }^{\circ} \mathrm{C} H_{c}$ increased drastically to about $7.7 \mathrm{kOe}^{13}$ and at $500{ }^{\circ} \mathrm{C}$ the $H_{c}$ reached about $10 \mathrm{kOe}$. A bright-field TEM micrograph of the 28-nm-thick $\mathrm{PrCo} \| \mathrm{Cr}$ film annealed at $500{ }^{\circ} \mathrm{C}$ is shown in Fig. 2. The as-deposited films are composed of a mostly amorphous PrCo layer with about 30\% volume fraction of crystallites and have small coercivity values because of the mostly amorphous PrCo layer. The film annealed at $500{ }^{\circ} \mathrm{C}$ shown in Fig. 2(a) contains nearly $100 \%$ crystallites with a grain size of $10 \mathrm{~nm}$ resulting in the large increase in the coercivity. The $\mathrm{x}$-ray diffraction pattern of the as-deposited 420-nm-thick PrCo film only shows the (110) diffraction peak of bcc $\mathrm{Cr}$ and no PrCo peaks are observed for the films with and without the $\mathrm{Cr}$ underlayer. This is due to the large amount of amorphous phase and small crystallites in the PrCo films. After annealing at $500{ }^{\circ} \mathrm{C}$ the PrCo layer is crystallized and we observe a few sets of peaks from the $\mathrm{x}$-ray diffraction pattern. The two most intense reflections are observed for $2 \theta=35.5^{\circ}$ and $2 \theta=42^{\circ}$. It is difficult to identify the crystal structure unambiguously from the $\mathrm{x}$-ray diffraction pattern because of the limited number of peaks and the several possible phases around the $\mathrm{Pr} / \mathrm{Co}$ atomic ratio of 3.5, these include the $\mathrm{PrCo}_{3}, \mathrm{Pr}_{2} \mathrm{Co}_{7}$ and $\mathrm{Pr}_{5} \mathrm{Co}_{19}$ phases. The detailed crystal structure of the annealed 28-nm-thick $\mathrm{PrCo} \| \mathrm{Cr}$ film was then investigated by nanodiffraction and HRTEM. It was found that the crystallites as shown in Fig. 2(b) have a hexagonal closed packed structure with frequent stacking faults. The nanodiffraction pattern can be well matched to the hexagonal closed packed structure.

In order to investigate whether the $\mathrm{Cr}$ underlayer was crucial for the enhancement of coercivity after annealing we compared the magnetic properties of a 420-nm-thick PrCo film with and without a $\mathrm{Cr}$ underlayer. It was observed that for the 420-nm-thick PrCo film with no $\mathrm{Cr}$ underlayer but

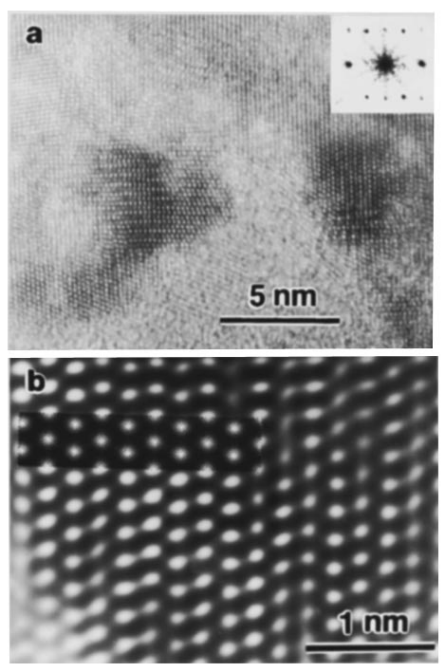

FIG. 2. (a) HRTEM image of $\mathrm{Cr}(80 \mathrm{~nm}) / \operatorname{PrCo}(28 \mathrm{~nm}) / \mathrm{Cr}(10 \mathrm{~nm})$ film annealed at $500{ }^{\circ} \mathrm{C}$. (b) HRTEM image of a crystallite in (a).

with a $\mathrm{Cr}$ overlayer of $10 \mathrm{~nm}$ the $H_{c}$ was about $9 \mathrm{kOe}$ and $M_{S} \approx 400 \mathrm{emu} / \mathrm{cc}$ after annealing at $500{ }^{\circ} \mathrm{C}$ whereas for the 420-nm-thick PrCo film with a Cr underlayer of $80 \mathrm{~nm}$ and a Cr overlayer of $10 \mathrm{~nm}$ the $H_{c}$ was about $7.5 \mathrm{kOe}$ and $M_{s} \approx 300 \mathrm{emu} / \mathrm{cc}$ after annealing at $500{ }^{\circ} \mathrm{C}$. Both the samples have squareness $S\left(M_{r} / M_{s}\right)=0.8$, but the coercivity squareness $S^{*}$ for the film with the Cr underlayer was 0.7 and for the film without the Cr underlayer the $S^{*}$ was about 0.35 . Hence we show that if crystallinity and grain growth are promoted a large increase in coercivity can be obtained for the PrCo films with and without the $\mathrm{Cr}$ underlayer, except that the films with a $\mathrm{Cr}$ underlayer have a better hysteresis loop squareness.

Next we report the magnetic properties of the asdeposited and annealed SmCo films with and without the $\mathrm{Cr}$ underlayer. Figure 3 shows the dependence of the coercivity on the SmCo layer thickness for the SmCo\|Cr films with and without the $\mathrm{Cr}$ underlayer. The as-deposited films show $H_{c}$ of about $500-2800$ Oe but after annealing at $500{ }^{\circ} \mathrm{C}$ for 20 min in vacuum there is a large increase in coercivity. The coercivity of the films with the Cr underlayer of $80 \mathrm{~nm}$ and a $\mathrm{Cr}$ overlayer of $10 \mathrm{~nm}$ annealed at $500{ }^{\circ} \mathrm{C}$ varies from 21 to 29 kOe with the maximum coercivity value obtained for 100nm-thick SmCo film. The $H_{c}$ of the SmCo film without the

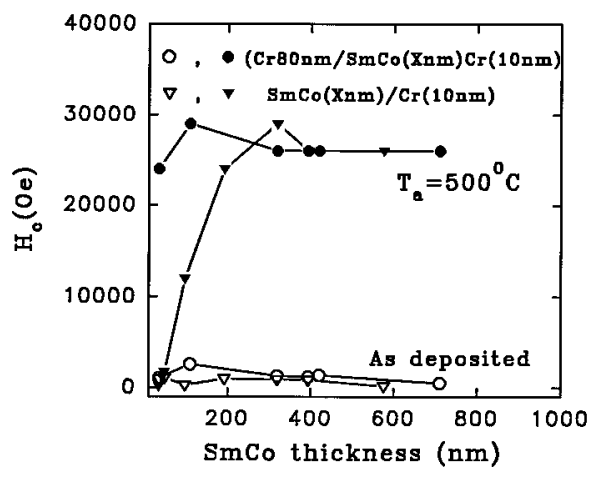

FIG. 3. Coercivity vs SmCo layer thickness for the as-deposited and annealed at $500{ }^{\circ} \mathrm{C} \mathrm{SmCo} \mathrm{films} \mathrm{with} \mathrm{and} \mathrm{without} \mathrm{a} \mathrm{Cr}$ underlayer. 


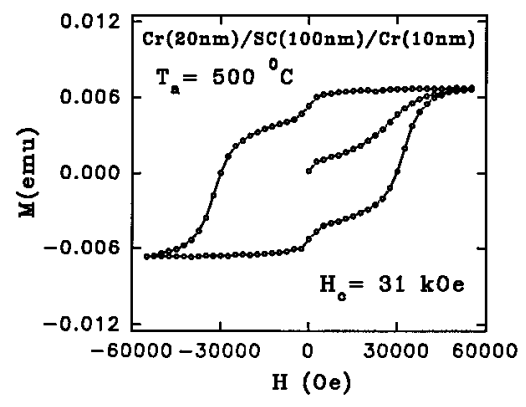

FIG. 4. Hysteresis loop for the 100-nm-thick SmCo film with a Cr underlayer of $20 \mathrm{~nm}$ annealed at $500{ }^{\circ} \mathrm{C}$.

$\mathrm{Cr}$ underlayer but with a $\mathrm{Cr}$ overlayer of $10 \mathrm{~nm}$ after annealing at $500{ }^{\circ} \mathrm{C}$ shows a large increase in coercivity only for SmCo films with thickness of at least $100 \mathrm{~nm}$ and above. A maximum $H_{c}$ value of $29 \mathrm{kOe}$ is obtained for 300-nm-thick $\mathrm{SmCo}$ film. For films without the $\mathrm{Cr}$ underlayer and $\mathrm{SmCo}$ layer thickness less than $100 \mathrm{~nm}$ the reason for no remarkable increase in coercivity after annealing is not clear at this point. This behavior is also observed for the PrCo film with thicknesses less than $100 \mathrm{~nm}$ and no $\mathrm{Cr}$ underlayer. The $M_{s}$ of the as-deposited SmCo films is about $400 \mathrm{emu} / \mathrm{cc}$ and after annealing at $500{ }^{\circ} \mathrm{C}$ the $M_{s}$ value for the films with the $\mathrm{Cr}$ underlayer of $80 \mathrm{~nm}$ is about $200 \mathrm{emu} / \mathrm{cc}$ and for the films without the $\mathrm{Cr}$ underlayer the $M_{s}$ is about $300 \mathrm{emu} / \mathrm{cc}$. For the SmCo films with a $\mathrm{Cr}$ underlayer thickness less than 80 $\mathrm{nm}$ there is not a significant change in the coercivity but the $M_{s}$ value of the films is slightly higher compared to the films with a $\mathrm{Cr}$ underlayer of $80 \mathrm{~nm}$. For the 100-nm-thick SmCo film with a $\mathrm{Cr}$ underlayer of only $20 \mathrm{~nm}$ the $M_{s}$ was about $250 \mathrm{emu} / \mathrm{cc}$ and the $H_{c}$ was about $31 \mathrm{kOe}$ after annealing at $500{ }^{\circ} \mathrm{C}$. The hysteresis loop for the annealed 100 -nm-thick $\mathrm{SmCo}$ film with a $\mathrm{Cr}$ underlayer of $20 \mathrm{~nm}$ measured with a maximum applied field of $55 \mathrm{kOe}$ parallel to the film surface is shown in Fig. 4. The film shows a coercivity of $31 \mathrm{kOe}$.

Liu et al. ${ }^{6}$ have observed that for the as-deposited films the $\mathrm{Cr}$ underlayer has grain size of about $24 \mathrm{~nm}$ and the SmCo layer consist of nanocrystallites about $5 \mathrm{~nm}$ diameter embedded in an amorphous matrix. Figure 5 compares the dark field images taken from the SmCo films with and without a $\mathrm{Cr}$ underlayer. The film with the $\mathrm{Cr}$ underlayer has grain sizes of about $20 \mathrm{~nm}$ while the film without the $\mathrm{Cr}$ underlayer has grains sizes of about $10 \mathrm{~nm}$. Nanodiffraction and HRTEM study to determine the crystal structure of the annealed films is in progress. The reason for the large enhancement in coercivity after annealing is very likely due to the crystallization of the SmCo grains.

\section{CONCLUSION}

In this work we have shown that 28-nm-thick PrCo films with a $\mathrm{Cr}$ underlayer of $80 \mathrm{~nm}$ after annealing at $500{ }^{\circ} \mathrm{C}$ have in-plane coercivity as high as $10 \mathrm{kOe}, S=0.9$ and $S^{*}=0.75$. The PrCo $\| \mathrm{Cr}$ films have magnetic properties and microstructure which show potential as high density recording media. Nanodiffraction and HRTEM studies show that the crystallites in the annealed film have a hexagonal closed packed

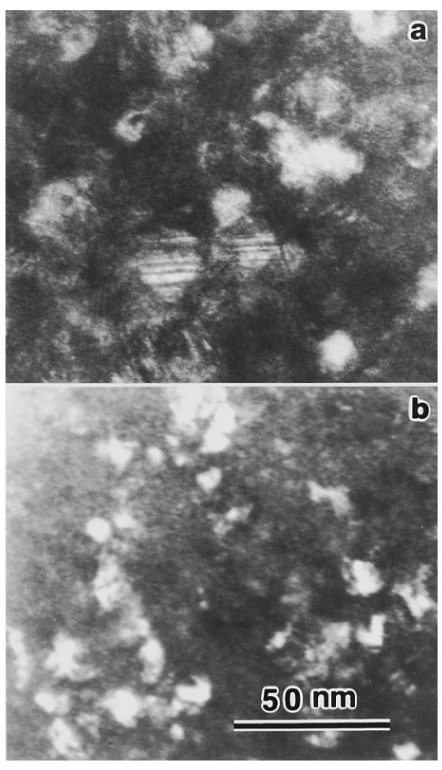

FIG. 5. Comparison of dark field images taken from a SmCo films (a) with the $\mathrm{Cr}$ underlayer and (b) without the $\mathrm{Cr}$ underlayer.

structure with frequent stacking faults. The enhancement of $H_{c}$ after annealing is likely due to the crystallization of the PrCo grain.

After annealing at $500{ }^{\circ} \mathrm{C} H_{c}$ as high as $31 \mathrm{kOe}$ was obtained for 100-nm-thick SmCo film with a $\mathrm{Cr}$ underlayer of $20 \mathrm{~nm}$ and $H_{c}$ of about $29 \mathrm{kOe}$ for 300-nm-thick SmCo film without the $\mathrm{Cr}$ underlayer. By post-annealing the asdeposited films with and without the $\mathrm{Cr}$ underlayer, crystallization, and grain growth is promoted for the SmCo films resulting in a large increase in coercivity.

\section{ACKNOWLEDGMENTS}

We are grateful for financial support from the National Storage Industry Consortium (NSIC) and the Advanced Research Projects Agency (ARPA) under Grant No. MDA97293-1-0009 and from the National Science Foundation under Grants No. DMR-9222976 and No. OSR-9255225.

${ }^{1}$ E. M. T. Velu and D. N. Lambeth, J. Appl. Phys. 69, 5175 (1991).

${ }^{2}$ Y. Okumura, H. Fujimori, O. Suzuki, N. Hosoya, X. B. Yang, and H. Morita, IEEE Trans. Magn. 30, 4038 (1994).

${ }^{3}$ D. J. Sellmyer, Z. S. Shan, Y. Liu, S. H. Liou, S. S. Malhotra, and B. W. Robertson, Acta Met. Mater. (in press).

${ }^{4}$ E. M. T. Velu, D. N. Lambeth, J. T. Thornton, and P. E. Russel, J. Appl. Phys. 75, 6132 (1994).

${ }^{5}$ Y. Okumura, O. Suzuki, H. Morita, X. B. Yang, and H. Fujimora, J. Magn. Magn. Mater. 146, 5 (1995).

${ }^{6}$ Y. Liu, B. W. Robertson, Z. S. Shan, S. Malhotra, M. J. Yu, S. K. Renukunta, S. H. Liou, and D. J. Sellmyer, IEEE Trans. Magn. 30, 4035 (1994).

${ }^{7}$ Y. Liu, B. W. Robertson, Z. S. Shan, S. H. Liou, and D. J. Sellmyer, J. Appl. Phys. 77, 3831 (1995).

${ }^{8}$ Y. Liu, D. J. Sellmyer, B. W. Robertson, Z. S. Shan, and S. H. Liou, IEEE Trans. Magn. (in press).

${ }^{9}$ H. C. Theuerer, E. A. Nesbitt, and D. D. Bacon, J. Appl. Phys. 40, 2994 (1969).

${ }^{10}$ F. J. Cadieu, T. D. Cheung, and L. Wickramasekera, J. Appl. Phys. 57, 4161 (1985).

${ }^{11}$ K. H. J. Buschow, J. Less-Common Metals 33, 311 (1973).

${ }^{12}$ A. E. Ray and K. J. Strnat, IEEE Trans. Magn. 11, 1429 (1975).

${ }^{13}$ S. S. Malhotra, Y. Liu, Z. S. Shan, S. H. Liou, D. C. Stafford, and D. J. Sellmyer (unpublished). 